\title{
CFD modeling of devolatilization and combustion of shredded tires and pine wood in rotary cement kilns
}

\author{
Peter Mtui \\ College of Engineering and Technology, University of Dar es Salaam, ar es Salaam, Tanzania
}

\author{
Email address: \\ plmtui@yahoo.com
}

\section{To cite this article:}

Peter Mtui. CFD Modeling of Devolatilization and Combustion of Shredded Tires and Pine Wood in Rotary Cement Kilns. American Journal of Energy Engineering. Vol. 1, No. 5, 2013, pp. 51-55. doi: 10.11648/j.ajee.20130105.11

\begin{abstract}
Computational fluid dynamics (CFD) has been used to study the devolatilization and combustion of large particles of shredded scrap tire "rubber" and pulverized pine wood "biomass" in a rotary cement kilns. The CFD model constitutes of modeling the hydrodynamics within the rotary kiln, heat transfer, devolatilization and co-combustion of rubber and biomass blends. Equivalent particle diameters of $1 \mathrm{~mm}$ and $2 \mathrm{~mm}$ for biomass and rubber, respectively, were used to simulate the process conditions and co-combustion in cement rotary kilns. The ratios of biomass substitution were varied from $5 \%$ to $20 \%$ on mass basis. The effect of the percentage of biomass content on the temperature distribution and devolatilization rate as well as wall heat transfer rate are presented. Results indicate that up to $20 \%$ biomass blend provides improved combustion characteristics compared with combustion of scrap tire alone. Further, the devolatilization rate was found to improve remarkably when scrap tire is blended with biomass. Most importantly, the biomass blend was found to increase the flame spreading and penetration, consequently improving the wall heat transfer rate, therefore providing favorable conditions for heat transfer to the cement clinker. The present study provides additional knowledge for future investigations on the use of biomass residues and some industrial wastes as alternative fuels for rotary cement kilns. That is, the use of alternative fuels in rotary cement kilns has a potential for economic improvement and environmental sustainability.
\end{abstract}

Keywords: CFD, Rotary Kiln, Scrap Tire, Biomass, Devolatilization, Combustion

\section{Introduction}

It has been reported by BP Statistical Review of World Energy [1] that the cement industry consumes approximately $2 \%$ of the world's primary energy consumption. Cembureau [2] pointed out that, fuel consumption in cement production accounts for nearly $30-40 \%$ of the total production costs. Traditionally, fossil fuels, such as coal and petroleum coke have been used as primary energy sources in the cement manufacturing industry. However, due to the recent increase of fossil fuel prices, and environmental concerns, the cement industry has increased the utilization of alternative fuels as a substitute for fossil fuels. For example, the most common alternative fuels in the cement industry are tire-derived fuels (TDF) and biomass residues. The utilization of coarse large solid particles as an alternative fuel in cement rotary kilns is an attractive option. Roller [3] pointed out that the refuse-derived fuel represents a significant quantity of energy therefore recovery of part of this energy would also reduce a growing environmental problem. The larger solid fuel particles in high temperatures environment in the rotary kiln provides longer retention times which is favorable for fuel burnout. Genon et al [4] have focused on pollutant emissions from waste derived fuel combustion in cement kilns while some researchers [5] carried out a study to investigate air requirement and energy input by partly replacing primary fuel by bone meal and sewage sludge.

Combustion of large fuel particles in rotary kilns is limited in the literature. Therefore, systematic investigation of percentage blend of pulverized biomass for a rotary kiln initially fired with shredded scrap tire as alternative fuels is of interest. Understanding the phenomena in a rotary kiln by experiments is not a trivial task because of the complex heat and mass transfer which involves chemical reactions during the process. The purpose of this work is therefore, to study the devolatilization and combustion of a blends of scrap tire and biomass and on the particles transport phenomena that involves heat and mass transfer within the rotary kiln. The study was carried out using computational 
fluid dynamics (CFD) modeling technique.

The pyrolysis technique is an alternative for reducing scrap tires and biomass and leads into the production of oils and black carbon. Tires are known to be composed mainly of rubbers, such as natural rubber, or styrene-butadiene rubber, as well as mineral oils and black carbon [6]. Thermal degradation of tires has been studied by Yang, et al [7] who reported that devolatilization rate is strongly dependent on temperature and the particle size.

Larsen et al [8] reported the devolatilization times of cylindrical tire rubber particles with diameters ranging from 7 to $22 \mathrm{~mm}$ and height of $35 \mathrm{~mm}$ at $840{ }^{\circ} \mathrm{C}$ in an inert atmosphere to range from 75 to 300 seconds. Depending on thickness and temperature of tire, the devolatilization times were found by Chinyama [9] to be 30-100 seconds for the rubber particle size range of $6-12 \mathrm{~mm}$ in air at temperature from 700 to $1000^{\circ} \mathrm{C}$. Generally, results reported in literature about devolatilization of large TDF particles show clear tendencies for devolatilization time to increase with increasing particle size and decrease with increasing temperature.

Previous work of Atal and Levendis [10] on the combustion of tire char was performed with a few $\mathrm{mg}$ of tire char particles in the range of $100-500 \mu \mathrm{m}$ size in thermogravimetric analyzers (TGA). For tire char with particle size of $500 \mu \mathrm{m}$, the char conversion times are reported to be well below $1 \mathrm{~s}$ in air and at $1200^{\circ} \mathrm{C}$.

Devolatilization of non-spherical pine wood particles with equivalent diameters ranging 10 to $45 \mathrm{~mm}$ in the temperature range $650^{\circ} \mathrm{C}$ to $850^{\circ} \mathrm{C}$ has been investigated by Diego et al [11]. The reported devolatilization times for 10 to $30 \mathrm{~mm}$ diameter particles were, for example, from 30 to 150 seconds at $850{ }^{\circ} \mathrm{C}$. Di Blasi and Branca [12] studied temperature profiles in cylindrical beech wood particles with lengths of $20 \mathrm{~mm}$ and diameters from 2 to $10 \mathrm{~mm}$. They reported the devolatilization time of 40 seconds at the bed temperature of 439 and $834{ }^{\circ} \mathrm{C}$. Di Blasi [13] and White et al. [14] have presented exhaustive review of kinetics models for biomass pyrolysis and report general tendencies that devolatilization times increase with increasing particle size and decrease with increasing temperatures.

\section{Model Description}

A three-dimensional geometry of the rotary kiln was constructed using Gambit software as per Table 1. A multiannular, multi-fuel burner was designed so that the shredded tire and pulverized biomass were independently introduced into the kiln by the fluidizing primary air. The proximate and ultimate analyses of the rubber are reported by Juma et al [15] and those of biomass suggested by Diego, et al [11] are contained in Table 2, both on dry basis. The process data and boundary conditions such as wall temperatures and wall emissivity factors were set appropriately in the model.
Table 1. Kiln data

\begin{tabular}{ll}
\hline Parameter & Value \\
\hline Inner diameter $(\mathrm{m})$ & 4.5 \\
Kiln length $(\mathrm{m})$ & 60 \\
Rotational speed $(\mathrm{rpm})$ & 4 \\
Tilt angle $(\mathrm{deg})$ & 3 \\
\hline
\end{tabular}

Table 2. Fuels data

\begin{tabular}{lll}
\hline Proximate Analysis & Rubber [15] & Biomass [11] \\
\hline Fixed carbon (\%wt) & 22.66 & 15.3 \\
Volatiles (\%wt) & 61.61 & 75.1 \\
Moisture (\%wt) & 1.72 & 8.3 \\
Ash (\%wt) & 14.01 & 1.3 \\
LHV (MJ/kg) & 34.2 & 18.7 \\
Ultimate Analysis & & \\
\hline C & 81.24 & 52.9 \\
H & 7.36 & 6.8 \\
O & 8.92 & 38.9 \\
N & 0.3 & 0.1 \\
S & 2.18 & 1.3 \\
\hline
\end{tabular}

\section{Model Development}

This section seeks to develop mathematical models for devolatilization and char combustion for the selected alternative fuels. The models are used under conditions similar to those in the material inlet end of cement rotary kilns.

\subsection{Inert Heating}

Inert heating of fuel particles takes place during which the particle temperature is less than the evaporation temperature or when all the volatiles have been consumed. The heating is mainly due to convection and radiation heat transfer.

$$
m_{p} C_{p} \frac{d T_{p}}{d t}=h A_{p}\left(T_{\infty}-T_{p}\right)+\varepsilon_{p} A_{p} \sigma\left(\theta_{R}^{4}-T_{p}^{4}\right)
$$

where $m_{p}$ is the mass of the particle, $C_{p}$ is the heat capacity of the particle, $A_{p}$ is the surface area of the particle, $T_{\infty}$ is the local gas phase temperature, $T_{p}$ is the particle temperature, $h$ is the convective heat transfer coefficient, $\varepsilon_{p}$ is the particle emmisivity, $\sigma$ is the Boltzmann constant and $\theta_{R}$ is the radiation temperature. The heat transfer coefficient $h$ is evaluated as:

$$
N u=\frac{h D_{p}}{k_{\infty}}=2.0+0.6 \operatorname{Re}_{D}^{1 / 2} \operatorname{Pr}^{1 / 3}
$$

where $k_{\infty}$ and $\operatorname{Pr}$ are respectively the thermal conductivity 
and Prandtl number of the gas phase.

\subsection{Devolatilization Model}

Devolatilization was modeled by the two competing rates model proposed by Kobayashi, et al [16] so that:

$$
\begin{aligned}
& R_{1}=A_{1} e^{-\left(E_{1} / R T_{p}\right)} \\
& R_{2}=A_{2} e^{-\left(E_{2} / R T_{p}\right)}
\end{aligned}
$$

where $R_{1}$ and $R_{2}$ are competing rates that may control the devolatilization over different temperature ranges so that the rate of devolatilization is given as:

$$
\frac{m_{v}(t)}{\left(1-f_{w, 0}\right)\left(m_{p, 0}-m_{a}\right)}=\int_{0}^{t}\left(\alpha_{1} R_{1}+\alpha_{2} R_{2}\right) \exp \left(-\int_{0}^{t}\left(R_{1}+R_{2}\right) d t\right) d t
$$

where: $m_{v}(t)=$ volatile yield at time $t$

$m_{p, 0}=$ initial mass of particle

$m_{a}=$ ash content in the particle

$\alpha_{1}, \alpha_{2}=$ model constants

$f_{w, 0}=$ mass fraction of volatiles initially present in the particle

\subsection{Char Combustion Model}

The aim of this section is to derive a model for char conversion in the rotary kiln, including the main rate limiting parameters for char conversion.

Surface char combustion is accounted for by using the Kinetic/Diffusion reaction rate model, which assumes that the surface reaction rate is determined either by kinetics or a diffusion rate. In this work, the model of Braum et al [17] and Field [18] is used such that the diffusion rate,

$$
R_{1}=C_{1} \frac{\left(\frac{\left(T_{P}+T_{\infty}\right)}{2}\right)^{3 / 4}}{D_{p}}
$$

and the kinetic rate

$$
R_{2}=C_{2} \exp \left(-E / R T_{p}\right)
$$

so that the rate of change of particle mass, $m_{p}$ is given by

$$
\frac{d m_{p}}{d t}=\pi D_{p}^{2} P_{0} \frac{R_{1} R_{2}}{R_{1}+R_{2}}
$$

where $P_{0}$ is the partial pressure of oxidant species in the gas surrounding the combusting particle and the kinetic rate $R_{2}$ incorporates the effects of chemical reaction on the internal surface of the char particle and pore diffusion. The particle size is assumed to remain constant at time $\Delta t$ while the density is allowed to decrease.

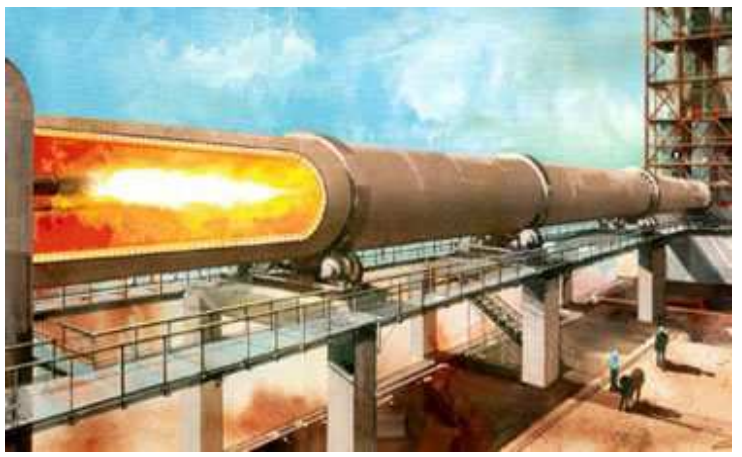

Figure 1. Typical rotary kiln showing the flame propagation and bed temperature

\section{Transport Phenomena}

CFD modeling of the thermo-chemical processes such as of reactive flows is governed by the continuity and momentum equations and includes the description of fluid flow, heat and mass transfer, and chemical reactions. The process fundamental governing equations are the conservation laws of mass, momentum, energy and species. The conservation equations can be generally written as [19]:

$$
\frac{\partial(\rho \varphi)}{\partial t}+\frac{\partial\left(\rho u_{j} \varphi\right)}{\partial x_{j}}=\frac{\partial}{\partial x_{j}}\left(\Gamma_{\varphi} \frac{\partial \varphi}{\partial x_{j}}\right)+S_{\varphi}
$$

where $\phi$ is a general variable such as velocity components, temperature, mass fraction, etc. For the above, $\rho$ is the fluid density, and $u$ is the fluid velocity vector. The variable $\Gamma_{\phi}$ represents the transport coefficient and $S_{\phi}$ is a source term. The conservative equations are discretized and solved iteratively so that the CFD technique enforces the conservation of mass, momentum, energy and species concentrations over the entire computational domain [20].

\section{Results and Discussions}

Results from this simulation are discussed for various blends of waste tire ("rubber") and wheat straw ("biomass"). Generally, the results show strong dependence on the quantity of biomass blend on the combustion characteristics in the rotary kiln.

Figure 2 shows the contour plots for the axial and radial temperature distributions in the kiln for various blends of biomass content from 5 to $20 \%$. Results indicate that larger quantities of biomass substitution improve the radial and axial temperature distribution. This phenomenon is probably due to higher volatiles content in biomass which enhances the reactivity of the rubber. Similarly, Figure 3 depicts the axial temperature profile along the center axis of the kiln length. Up to $20 \%$ biomass substitution shows similar temperature profiles as for a kiln fired with scrap tire alone. 
Figure 4 illustrates the rate of devolatilization for scrap tire blended with biomass. Results show remarkably higher devolatilization rate as the biomass is increased to $20 \%$. As expected, the higher volatiles content in biomass enhances the overall devolatilization of the scrap tire ("rubber"). Thus, the enhanced devolatilization rate improves the char burn-rate as shown in Figure 5. Similarly, Figure 6 shows the improved wall heat transfer rate for larger quantities of biomass substitution which is consistent with increased radial temperature distribution illustrated in Figure 2.

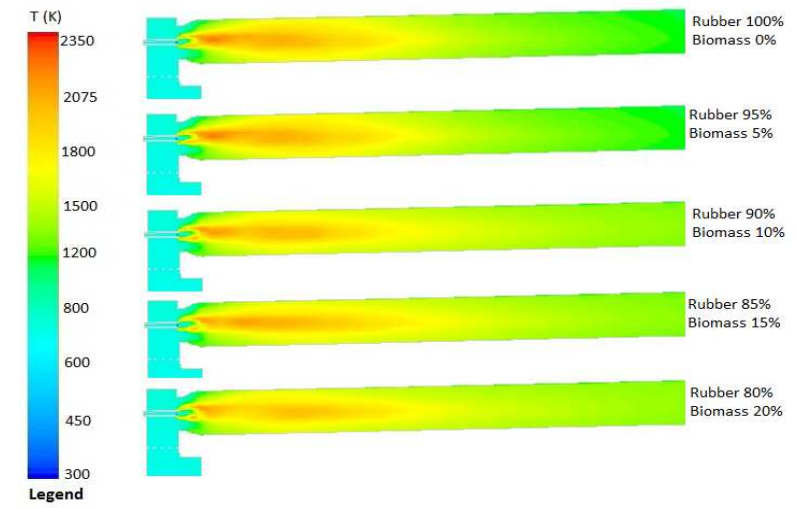

Figure 2. Temperature distribution along the length of the kiln with varying biomass blend

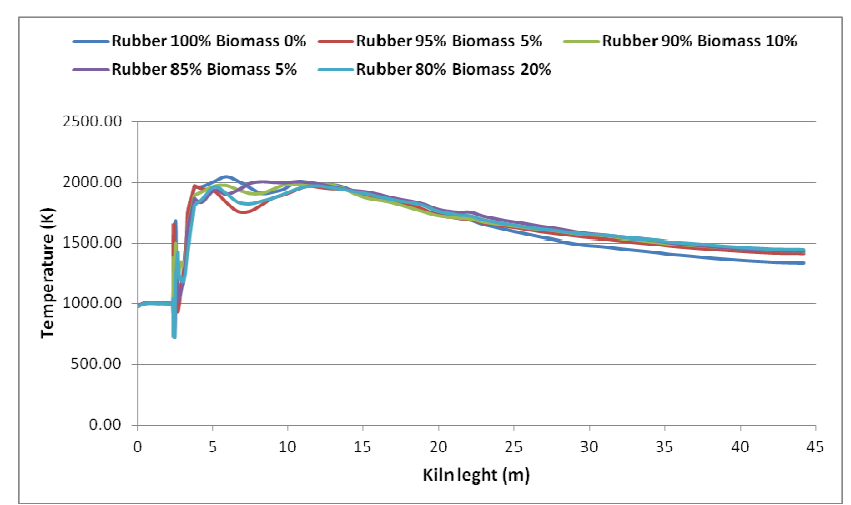

Figure 3. Temperature profile along the center axis of kiln length with varying biomass blend

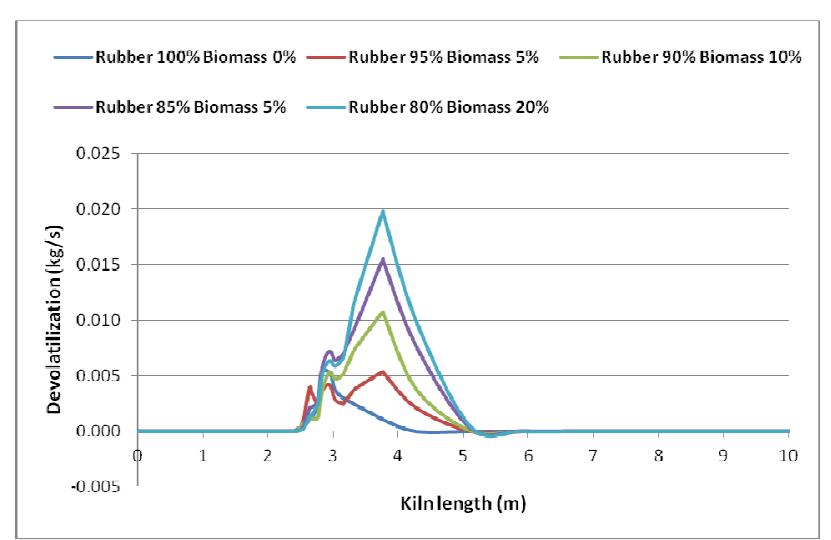

Figure 4. Devolatilization rate along the center axis of kiln length with varying biomass blend

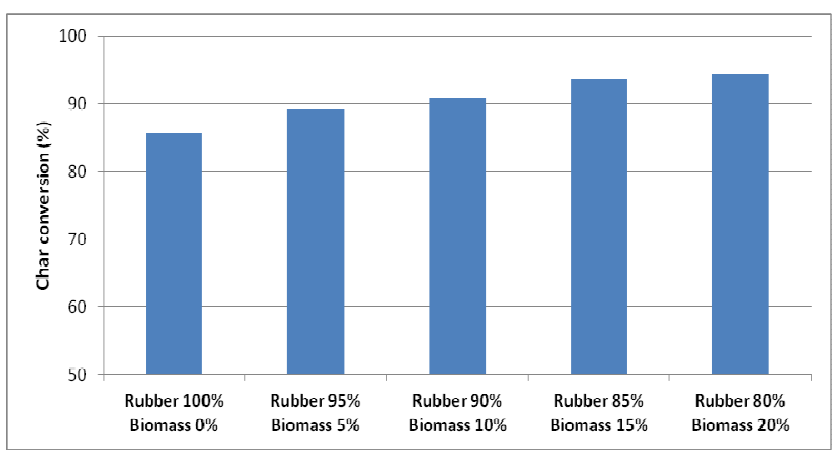

Figure 5. Char conversion during co-combustion

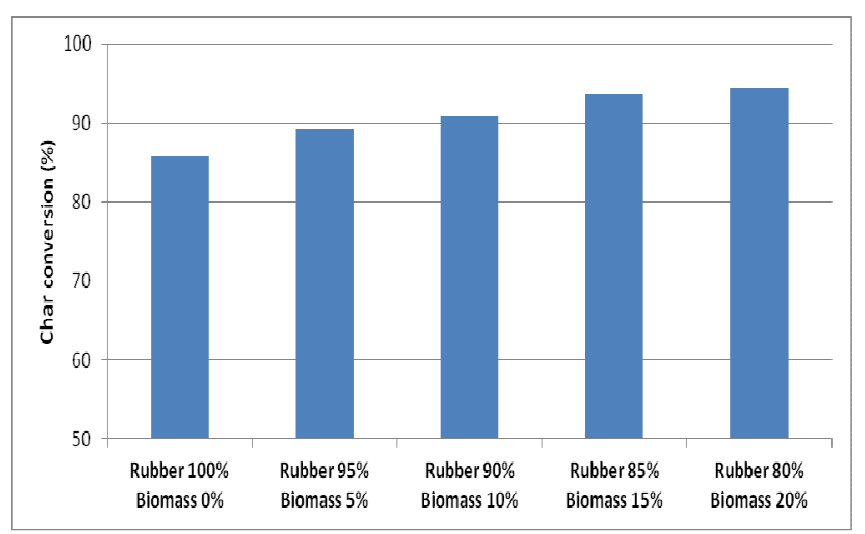

Figure 6. Kiln wall heat transfer rate

\section{Conclusion}

Computational fluid dynamics has been used to study the devolatilization and co-combustion of shredded scrap tire and pulverized pine wood in rotary kiln. The biomass blend was varied from $5 \%$ to $20 \%$ in order to investigate the influence of the quantity of the biomass blend on the combustion characteristics of rotary cement kiln originally fired with shredded tires.

Results indicate a significant increase in axial and radial flame distribution in the rotary kiln as the biomass content was increased from $5 \%$ to $20 \%$. Consequently, the wall heat transfer rate increases as the biomass quantity was increased. The increased heat transfer rates improves the performance in the cement kiln in transferring heat to the cement clinker and improve the performance of the kiln. Further, the increased rate of devolatilization with larger quantity of biomass substitution assists the thermal degradation of the waste tire therefore accelerates the char burnout. The co-combustion of biomass in rotary cement kilns fired with scrap tire may be thought of as an efficiently way to improve the reactivity of scrap tire fuel.

Overall conclusion is that co-combustion of waste tire with biomass substitution nearly up to $20 \%$ provides improved combustion characteristics, therefore, offering an opportunity of using alternative fuel blends in rotary cement kilns. 


\section{References}

[1] BP Statistical Review of World Energy; June 2009, http://www.bp.com.

[2] Cembureau,: Alternative Fuels in Cement Manufacture; 1997, http://www.cembureau.be

[3] R.C. Poller, Reclamation of waste plastics and rubber recovery of materials and energy, J. Chem. Tech. Biotechnol. 30_1980.152-160.

[4] G. Genon and E. Brizio, "Perspectives and limits for cement kilns as a destination for RDF," Waste Management, Vol. 28, no. 11, pp. 2375-2385, Nov. 2008.

[5] U. Kaantee, R. Zevenhoven, R. Backman and M. Hupa, "Cement manufacturing using alternative fuels and the advantages of process modelling," Fuel Processing Technology, Vol. 85, no. 4, pp. 293-301, Mar. 2004.

[6] Conesa J.A., Font R., Marcilla R. Mass spectrometry validation of a kinetic model for the thermal decomposition of tyre wastes. Journal of Analytical and Applied Pyrolysis 43; pp. 83-96; 1997.

[7] Yang J., Tanguy P. A., Roy C. Heat transfer, mass transfer and kinetics study of the vacuum pyrolysis of a large used tire particle. Chemical Engineering Science 50; pp. 1909$1922 ; 1995$

[8] Larsen, M. B.; Schultz, L.; Glarborg, P.; Skaarup-Jensen, L.; Dam-Johansen, K.; Frandsen, F.; Henriksen, U. Fuel 2006, $85,1335-1345$.

[9] Chinyama, M. P. M; Lockwood, F. C. J. Energy Inst. 2007, $80(3), 162-167$
[10] Atal, A.; Levendis, Y. A. Fuel 1995, 74 (11), 1570-1581

[11] de Diego L. F., F. García-Labiano, A. Abad, P. Gayán, J. Adánez Coupled drying and devolatilization of nonspherical wet pine wood particles in fluidized beds. Journal of Analytical and Applied Pyrolysis 65 (2002) 173-184

[12] Di Blasi, C.; Branca, C. Energy Fuels 2003, 17, 247-254

[13] C. Di Blasi, Modeling chemical and physical processes of wood and biomass pyrolysis, Progress in Energy and Combustion Science 34 (2008) 47-90

[14] J.E. White, W.J. Catallo, B.L. Legendre, Biomass pyrolysis kinetics: a comparative critical review with relevant agricultural residue case studies, Journal of Analytical and Applied Pyrolysis 91 (2011) 1-33.

[15] M. Juma, Z. Koreňová, J. Marks, J. Annus, L. Jelemensky. Pyrolysis and Combustion of Scrap Tires Petroleum \& Coal 48 (1), 15-26, 2006

[16] H. Kobayashi, J. B. Howard, and A. F. Saro Coal Devolatilization at High Temperatures. In 16th Symp. (Int'1.) on Combustion. The Combustion Institute, 1976

[17] Braum M. M. and P. J. Street. Predicting the Combustion Behaviour of Coal Particles. Combustion Science and Technology, 3(5), 231-243. (1971)

[18] Field M. A. Rate of Combustion of Size-Graded Fractions of Char from a Low Rank Coal between $1200 \mathrm{~K}$ and $2000 \mathrm{~K}$. Combustion and Flame, 13, 237-252. (1969)

[19] Elaine S. Oran and Jay P. Boris Numerical Simulation of Reactive Flow, Cambridge University Press, Second Edition, Second edition (2001)

[20] Fluent 12 User Guide Copyright @2009 by ANSYS, Inc. 